\title{
Dengue virus-like particles mimic the antigenic properties of the infectious dengue virus envelope
}

\author{
Stefan W. Metz ${ }^{1 *} \mathbb{D}$, Ashlie Thomas ${ }^{1}$, Laura White', Mark Stoops ${ }^{1}$, Markus Corten ${ }^{1}$, Holger Hannemann² \\ and Aravinda M. de Silva ${ }^{1}$
}

\begin{abstract}
Background: The 4 dengue serotypes (DENV) are mosquito-borne pathogens that are associated with severe hemorrhagic disease. DENV particles have a lipid bilayer envelope that anchors two membrane glycoproteins prM and E. Two E-protein monomers form head-to-tail homodimers and three E-dimers align to form "rafts" that cover the viral surface. Some human antibodies that strongly neutralize DENV bind to quaternary structure epitopes displayed on $\mathrm{E}$ protein dimers or higher order structures forming the infectious virus. Expression of prM and $\mathrm{E}$ in cell culture leads to the formation of DENV virus-like particles (VLPS) which are smaller than wildtype virus particles and replication defective due to the absence of a viral genome. There is no data available that describes the antigenic landscape on the surface of flavivirus VLPs in comparison to the better studied infectious virion.
\end{abstract}

Methods: A large panel of well characterized antibodies that recognize epitope of ranging complexity were used in biochemical analytics to obtain a comparative antigenic surface view of VLPs in respect to virus particles. DENV patient serum depletions were performed the show the potential of VLPs in serological diagnostics.

Results: VLPs were confirmed to be heterogeneous in size morphology and maturation state. Yet, we show that many highly conformational and quaternary structure-dependent antibody epitopes found on virus particles are efficiently displayed on DENV1-4 VLP surfaces as well. Additionally, DENV VLPs can efficiently be used as antigens to deplete DENV patient sera from serotype specific antibody populations.

Conclusions: This study aids in further understanding epitopic landscape of DENV VLPS and presents a comparative antigenic surface view of VLPs in respect to virus particles. We propose the use VLPs as a safe and practical alternative to infectious virus as a vaccine and diagnostic antigen.

Keywords: Dengue virus, VLP, Epitopes, Serum depletions

\section{Background}

Dengue viruses (DENV) are mosquito-borne flaviviruses responsible for dengue fever and dengue hemorrhagic fever $[1,2]$. DENVs are endemic in over 125 countries and its global distribution is expected to expand due to urbanization and other environmental factors that favor the mosquito vector [3]. The DENV complex consists of 4 antigenically distinctive serotypes (DENV1-4). Infectious DENV particles contain a positive stranded RNA

\footnotetext{
* Correspondence: swmetz@med.unc.edu

${ }^{1}$ Department of Microbiology and Immunology, University of North Carolina, Chapel Hill, USA

Full list of author information is available at the end of the article
}

genome and capsid proteins surrounded by a lipid envelope, which has two membrane glycoproteins designated as pre-membrane (prM) and envelope (E). The outer surface of the mature, infectious virus has a smooth surface covered by E protein homodimers [4]. On the viral surface, units of three $\mathrm{E}$ protein homodimers assemble into raft-like structures and 30 rafts are packed tightly to create a protein coat with icosahedral symmetry. The $\mathrm{E}$ protein mediates viral attachment and entry into cells. Additionally, the E protein is the major target of neutralizing and protective human antibodies. Recent studies have demonstrated that most human antibodies that strongly neutralize DENVs bind to quaternary structure 
E protein epitopes containing regions from 2 or more proteins packed on the viral surface [5-8]. In other words, many human antibodies target $\mathrm{E}$ protein epitopes displayed on the viral surface but not on individual $\mathrm{E}$ protein subunits. Soluble E protein subunit antigens are, therefore, considered to be poor vaccine immunogens because they lack higher order protein structures and epitopes displayed on the intact virus. When flavivirus prM and E proteins are co-expressed in cells, these proteins assemble into virus-like particles (VLPs) that are secreted from cells. Flavivirus VLPs have been produced in a wide variety of expression platforms such as plants, insect cells, bacteria, yeast and mammalian cells. Flavivirus VLPs, which do not contain a viral nucleocapsid or genomic RNA, are smaller than intact virions [9-12]. VLPs, often, share structural similarities and physicochemical features of the native virus, but are superior in terms of safety, and ease of production and purification [10]. VLPs have proven to be effective vaccine antigens in preclinical or early stage clinical studies with different enveloped viral pathogens such as West Nile virus, Tickborne encephalitis virus, Japanese encephalitis virus, Zika virus, Chikungunya virus, Influenza virus and Dengue virus [10-17]. For DENV VLPs, no data is available on the display and presentation of epitopes of varying complexity recognized by human neutralizing antibodies. Some structural information is available for tick-borne encephalitis virus (TBEV) VLPs [12]. The low-resolution cryo-EM image based reconstruction of TBEV VLPs indicates that the number and organization of $E$ proteins on the VLPs are different from the infectious virus. Even though TBEV VLPs are heterogeneous in size, investigators analyzed a uniform population of particles that were smaller than virions and concluded that VLPs contain 30 E-homodimers assembled in a $T=1$ icosahedral lattice [12]. It is unclear if quaternary structure antibody epitopes, especially those containing residues from different adjacent E homo-dimers, are displayed similarly on VLPs and the larger infectious virions [12].

In this study we describe in detail the properties of epitopes present on DENV VLPs of all 4 serotypes using a large panel of well-defined human mAbs and immune sera from dengue patients. We directly compare the antigenic features of DENV VLPs to whole virions and explore their use as tools in serologic assays. Our results show the equivalence between viruses and VLPs in a setting that is particularly relevant for flavivirus vaccine development, diagnostics and understanding the difference between virus and VLPs.

\section{Methods}

\section{Production of DENV VLPs} Cells and viruses

Vero-81 cells were maintained at $37{ }^{\circ} \mathrm{C}$ as a monolayer in Dulbecco's modified Eagle's medium (DMEM, Gibco) supplemented with $5 \%$ fetal bovine serum (FBS), 1\% non-essential amino acids, $100 \mathrm{U} / \mathrm{ml}$ penicillin and $100 \mu \mathrm{g} / \mathrm{ml}$ streptomycin. Culture supernatants of DENV1 WestPac-74, DENV2 S-16803, DENV3 CH53489 and DENV4 TVP-376 virus strains were used to determine antibody binding and neutralizing activity of depleted and undepleted serum. Purified DENV virus preparations were obtained according to previously described protocols [18].

\section{DENV virus-like particle production}

The DENV virus-like particles (VLPs) were produced and kindly provided by The Native Antigen Company, Kidlington, UK. In short: recombinant dengue virus-like particles consisting of DENV prM and E proteins were transiently expressed in suspension culture adapted HEK293 cells. Three days post transfection culture supernatant was cleared by centrifugation and concentrated by tangential flow filtration. In a first step VLPs were purified by a 2-step discontinuous sucrose gradient with $20 \%$ and $40 \%$ sucrose densities. After a $6 \mathrm{~h}$ spin at $25,000 \mathrm{rpm}$ in a SW28 rotor at $10{ }^{\circ} \mathrm{C}$ the $20 \%-40 \%$ interphase was harvested by needle-stick. As a second purification step ion exchange chromatography (Q Sepharose High Performance; GE Healthcare) was used in negative mode once. VLPs were further purified by size exclusion chromatography (Toyopearl HW-65F) which also provided exchange of buffers to storage buffer. Purified DENV1-3 VLPs were stored in $10 \mathrm{mM}$ sodium phosphate, $20 \mathrm{mM}$ sodium citrate, $154 \mathrm{mM}$ sodium chloride, pH 7.4. DENV4 VLPs were stored in Dulbecco's phosphate buffered saline (DPBS) pH 7.4 containing $30 \%$ sucrose. VLP samples were stored at $-80{ }^{\circ} \mathrm{C}$.

\section{Virus and VLP analysis by western blot}

Purified VLP samples were subjected to sodium dodecyl sulphate polyacrylamide electrophoresis (SDS-PAGE) and analyzed by western blot (WB) and Coomassie Brilliant Blue (CBB) staining. 500 ng of DENV VLP or purified DENV virus [18] were loaded into a gel loading buffer (Biorad) supplemented with SDS. Samples were boiled for 10 mins at $95{ }^{\circ} \mathrm{C}$ and subsequently spun down at full speed for 2 mins. Following electrophoresis, separated protein fractions were transferred to a nitrocellulose membrane and blocked in blocking buffer (3\% skim milk in phosphate buffered saline (PBS) $+0.05 \%$ Tween-20). Blocked membranes were incubated with $0.5 \mu \mathrm{g} / \mathrm{ml} 1 \mathrm{M} 7 \mathrm{mAb}$ or $2 \mathrm{G} 3 \mathrm{mAb}$ in blocking buffer for $1 \mathrm{~h}$ at $37{ }^{\circ} \mathrm{C}$. Next, membranes were washed and treated with (1:1000 in blocking buffer) APconjugated anti-human IgG for $1 \mathrm{~h}$ at $37{ }^{\circ} \mathrm{C}$. After washing, membranes were developed by NBT/BCIP AP substrate (Thermo Scientific). 
Epitope analysis by enzyme-linked immunosorbent assay $100 \mathrm{ng} /$ well of 1M7 or 4G2 mAb was coated onto Highbinding Microlon plates (Greiner) in $0.1 \mathrm{M}$ bicarbonate buffer $\mathrm{pH} 9.6$ overnight at $4{ }^{\circ} \mathrm{C}$. Plates were washed 3 times with PBS $+0.1 \%$ Tween- 20 and blocked with PBS $+3 \%$ skim milk $+0.05 \%$ Tween- 20 for $1 \mathrm{~h}$ at $37{ }^{\circ} \mathrm{C}$. Next, plates were washed and incubated with serially diluted purified virus or VLPs (of 2 separate preparations) in blocking buffer for $1 \mathrm{~h}$ at $37^{\circ} \mathrm{C}$. After washing, the $1 \mathrm{M} 7$ coated plates were incubated with the indicated serially diluted mouse derived mAbs and the 4G2 coated plates were incubated with indicated serially diluted human mAbs (Table 1 ) for $1 \mathrm{~h}$ at $37^{\circ} \mathrm{C}$. After washing, mouse $\mathrm{mAb}$ treated wells were incubated with 1:1000 antimouse IgG-AP conjugated (Sigma) and human mAb treated wells were incubated with 1:2500 anti-human IgG-AP conjugated (Sigma). Plates were subsequently washed and developed using AP-substrate (Sigma). Absorbance was measured at $405 \mathrm{~nm}$.

The relative epitope display of each mAb tested was determined for both the purified virus as the VLPs of each serotype. The binding of all $\mathrm{mAbs}$ was normalized against the binding of 1F4 for DENV1, 2D22 for DENV2, $5 \mathrm{~J} 7$ for DENV3 and 5H2 for DENV4 to determine the relative epitope display of all other mAbs. The normalized increase or decrease in mAb binding was compared between virus and VLPs to give an indication of which epitopes are displayed better on the virus and VLP.

\section{DTO00 serum depletion}

DT000 sera was derived from an individual $>10$ years post a secondary DENV infection (Table 1) and was diluted 1:10 in PBS and subjected the serum depletion using DENV purified virus antigen or DENV VLPs (The Native Antigen Company). $100 \mu \mathrm{g}$ of $1 \mathrm{M} 7 \mathrm{mAb}$ was conjugated to $10 \mathrm{mg}$ of Tosylactivated M280 magnetic Dynabeads (Invitrogen) using manufacturers protocol. 1 M7 coated beads were blocked with $1 \%$ bovine serum albumin (BSA) in PBS for $1 \mathrm{~h}$ at $37^{\circ} \mathrm{C}$. The beads were washed 3 times with blocking buffer and incubated on a rotator with $100 \mu \mathrm{g}$ in $500 \mu \mathrm{l}$ blocking buffer of purified DENV antigen, DENV VLPs or BSA for $1 \mathrm{~h}$ at $37{ }^{\circ} \mathrm{C}$. Next, the beads were washed 3 times with PBS and cross-linked with 4\% PFA in $250 \mu \mathrm{l}$ PBS for 30 mins at room temperature. Next, the beads were washed 4 times in PBS, resuspended in $100 \mu \mathrm{l}$ PBS and subsequently divided over two tubes for two rounds of depletion. $500 \mu \mathrm{l}$ of diluted serum was incubated with the beads for $1 \mathrm{~h}$ at $37{ }^{\circ} \mathrm{C}$ on a rotator. Next, the serum was transferred to the second tube of beads for the second round of depletion. Finally, the depleted serum was stored at $4{ }^{\circ} \mathrm{C}$ for

Table 1 Monoclonal antibody characterization

\begin{tabular}{|c|c|c|c|c|c|c|c|c|c|c|}
\hline \multirow[t]{2}{*}{ mAb/ polyclonal sera } & \multirow[t]{2}{*}{$\mathrm{M} / \mathrm{H} / \mathrm{C}$} & \multirow[t]{2}{*}{ Binding } & \multirow[t]{2}{*}{ Neutralization (W/M/S) } & \multirow[t]{2}{*}{ Binding region } & \multicolumn{5}{|c|}{ Binding DENV serotypes } & \multirow[t]{2}{*}{ Ref } \\
\hline & & & & & DV1 & DV2 & DV3 & DV4 & ZIKV & \\
\hline $4 G 2$ & M & $\mathrm{F}-\mathrm{CR}$ & W & $\mathrm{D} \| \mathrm{FL}$ & ++ & ++ & +++ & +++ & +++ & {$[26]$} \\
\hline 1F4 & $\mathrm{H}$ & DV1 & DV1:S & DI/DII hinge Q & +++ & - & - & - & - & [7] \\
\hline $12 C 1.5$ & M & $D-C R$ & DV:S & DIII & ++ & ++ & +++ & ++ & - & [27] \\
\hline $1 C 19$ & $\mathrm{H}$ & $D-C R$ & DV:M & $\mathrm{D} \| \mathrm{FL} / \mathrm{BC}$ & ++ & ++ & ++ & + & ++ & [28] \\
\hline $2 \mathrm{D} 22$ & $\mathrm{H}$ & DV2 & DV2:S ZIKV:W & D\|/DII Q & - & ++ & - & - & - & {$[5,29]$} \\
\hline $5 J 7$ & $\mathrm{H}$ & DV3 & DV3:S & $\mathrm{DI} / \mathrm{D} \| \mathrm{Q}$ & - & - & +++ & - & - & [23] \\
\hline $5 \mathrm{H}_{2}$ & C & DV4 & DV4:S & $\mathrm{DI} Q$ & - & - & - & + & - & [24] \\
\hline $1 \mathrm{M7}$ & $\mathrm{H}$ & $\mathrm{F}-\mathrm{CR}$ & M & DII FL & +++ & ++ & +++ & +++ & +++ & {$[30]$} \\
\hline A11 (EDE2) & $\mathrm{H}$ & $\mathrm{F}-\mathrm{CR}$ & DV:S ZIKV:W & DI/DII/DIII Q & +++ & +++ & +++ & +++ & + & [31] \\
\hline$B 7$ (EDE2) & $\mathrm{H}$ & $\mathrm{F}-\mathrm{CR}$ & DV:S ZIKV:W & DI/DII/DIII Q & +++ & +++ & +++ & +++ & + & [31] \\
\hline C8 (EDE1) & $\mathrm{H}$ & $\mathrm{F}-\mathrm{CR}$ & DV:S ZIKV:S & DII/DII Q & +++ & +++ & +++ & +++ & ++ & [31] \\
\hline $\mathrm{C10}$ (EDE1) & $\mathrm{H}$ & $\mathrm{F}-\mathrm{CR}$ & DV:S ZIKV:S & D\|/D\|ll Q & +++ & +++ & +++ & +++ & ++ & [31] \\
\hline $3 \mathrm{H} 5$ & M & DV2 & DV2:S & DIII LR & - & +++ & - & - & - & {$[32]$} \\
\hline $8 A 1$ & M & DV3 & DV3:S & DIII & - & - & +++ & - & - & [33] \\
\hline DV4 126 & $\mathrm{H}$ & DV4 & DV4:S & DI/DII hinge Q & - & - & - & +++ & - & {$[8]$} \\
\hline DV4 131 & $\mathrm{H}$ & DV4 & DV4:S & DI/D\|l hinge Q & - & - & - & +++ & - & {$[8]$} \\
\hline DV4 141 & $\mathrm{H}$ & DV4 & None & DIII & - & - & - & +++ & - & [8] \\
\hline DT000 & $\mathrm{H}$ & D-CR & DV:S ZIKV:W & & +++ & +++ & +++ & ++ & - & [21] \\
\hline
\end{tabular}

Dengue specific monoclonal antibodies. A panel of well-defined mouse, human or chimpanzee (M/H/C) derived Mabs were used to characterize sRecE epitopes. Flavivirus cross reactive (F-CR), dengue cross reactive (D-CR), weakly, moderately or strong (W/M/S) neutralizing, E-domain I, II, III (DI, DII, DIII), fusion loop (FL), $\mathrm{BC}$-loop $(\mathrm{BC})$, lateral ridge $(\mathrm{LR})$, quaternary $(\mathrm{Q})$ 
further analysis by ELISA and flow based vero cell neutralization assay.

\section{DENV specific IgG ELISA}

Microlon ELISA plates (Greiner) were coated with $100 \mathrm{ng} /$ well of $4 \mathrm{G} 2 \mathrm{mAb}$ in $0.1 \mathrm{M}$ bicarbonate buffer $\mathrm{pH} 9.6$ overnight at $4{ }^{\circ} \mathrm{C}$. The plates were blocked with PBS $+3 \%$ skim milk $+0.05 \%$ Tween-20 for $1 \mathrm{~h}$ at $37{ }^{\circ} \mathrm{C}$. Next, the plates were washed 3 times with PBS $+1 \%$ Tween-20 and incubated with 1:10 diluted virus culture supernatant in blocking buffer for $1 \mathrm{~h}$ at $37{ }^{\circ} \mathrm{C}$. After washing, the plates were incubated with depleted or undepleted DT000 or DT168 serum (final concentration 1:50 diluted in blocking buffer) for $1 \mathrm{~h}$ at $37^{\circ} \mathrm{C}$. Next, the plates were washed and incubated with 1:2500 antihuman IgG-AP conjugated (Sigma) for 45 mins at $37^{\circ} \mathrm{C}$. The plates were washed and developed with APsubstrate (Sigma) and the absorbance was measured at $405 \mathrm{~nm}$.

\section{Vero cell neutralization assay}

The neutralizing capacity of depleted and undepleted DT000 serum was determined by flow based neutralization assay as previously described $[19,20]$. In short: 25000 Vero cells/well were seeded in a 96-wells flat-bottom culture plate and incubated overnight at $37^{\circ}$ C. Depleted and undepleted sera were serially diluted in OptiMem (Gibco) and incubated for 45 mins at $37{ }^{\circ} \mathrm{C}$ with the appropriate amount of virus (resulting in 15\% of infected cells - amount previously determined). Cells were washed with OptiMem and overlayed with the virus/serum mix for $2 \mathrm{~h}$ at $37{ }^{\circ} \mathrm{C}$. Next, cells were washed and overlaid with Vero cell growth medium and incubated overnight at $37{ }^{\circ} \mathrm{C}$. The next day, cells were detached using trypsin (Gibco) and transferred to a 96wells round bottom well plate. Cells were fixed in $4 \%$ paraformaldehyde in PBS for 10 mins at room temperature. Cells were subsequently washed in permeabilization buffer and blocked with 1\% normal mouse serum in PBS for 30 mins at room temperature. The cells were treated with Alexa fluor 488 conjugated anti-prM Mab $2 \mathrm{H} 2$ and diluted 1:400 in blocking buffer for $1 \mathrm{~h}$ at $37^{\circ} \mathrm{C}$. Cells were washed in permeabillization buffer and finally resuspended in PBS $+1 \%$ FBS. The percentage of infected cells was determined by flow cytometry using a Guava ${ }^{\circ}$ Flow Cytometer (EMD Millipore) and the neutralizing efficiency of the sera was expressed as neut 50 values (the dilution where $50 \%$ of the virus was neutralized) calculated using GraphPad Prism software.

\section{Transmission electron microscopy}

Discharged copper 400 mesh formvar carbon coated grids (Ted Pella Inc., Redding, CA, USA) were loaded with $15 \mu \mathrm{l}$ of purified DENV VLPs for 5 mins at room temperature. The grids were washed in MilliQ water and stained for $30 \mathrm{~s}$ with $2 \%$ uranyl acetate. Excess uranyl acetate was removed by filter paper. The grids were finally air-dried at RT and observed with a LEO 910 transmission electron microscope (Zeiss).

\section{Results}

\section{Expression and purification of DENV VLPs}

DENV1-4 prM-E sequences were expressed in mammalian HEK 293 suspension cultures and purified by sucrose gradient and ion-exchange chromatography. Purified VLP fractions were subjected to SDS-PAGE and analyzed by Coomassie stain (CBB; Fig.1a) and Western Blot (WB) using a cross-reactive (CR) human derived anti-E mAb $1 \mathrm{M} 7$ and anti-prM 2G3 (Fig. 1b). All virus and VLP samples showed a protein band of $\sim 55 \mathrm{kDa}$, corresponding to the estimated molecular weight of the DENV E protein. There were some slight differences observed in molecular weight between the 4 serotypes, possibly due to differences in the number of $\mathrm{N}$-linked glycans. However, the size differences were consistent

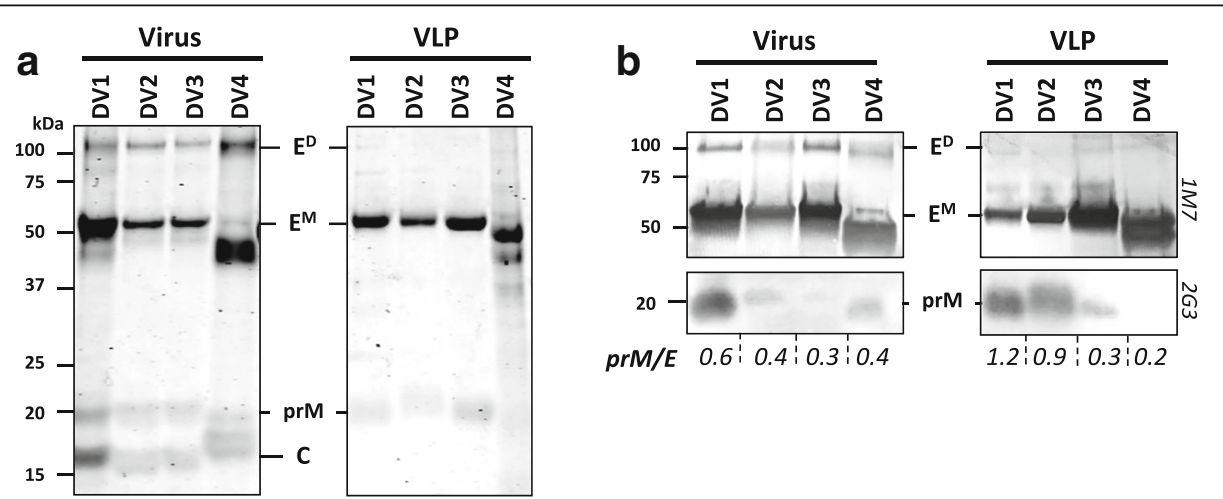

Fig. 1 Expression and characterization of DENV1-4 VLPS. Purified virus and VLPs were subjected to SDS-PAGE and analyzed with (a) CBB and (b) WB using anti-E $1 \mathrm{M} 7$ and anti prM $2 \mathrm{G} 3$ mAbs. E-dimers $\left(\mathrm{E}^{\mathrm{D}}\right)$, E-monomers $\left(\mathrm{E}^{\mathrm{M}}\right)$, prM and capsid (c) proteins are indicated. The prM/E ratio is indicated below panel $B$ and is determined using ImageJ software 
for the virus samples and the VLP samples. The levels of prM seemed to differ between purified virus and VLP samples. DENV1 and DENV2 VLPs appear to contain more prM than their virus counterpart, while DENV4 VLPs had lower prM levels compared to DENV4 purified virus as determined by the $\mathrm{prM} / \mathrm{E}$ ratio. However, the difference in prM content and maturation differences between VLP serotypes need to be further analyzed in other more focused studies. E-dimer fractions appeared more prominent in the virus samples as compared to VLPs.

Negative staining followed by transmission electron microscopy (TEM) revealed that the DENV VLPs are fairly monodispersed, but heterogeneous in morphology and size (Fig. 2). The VLPs appear as semi-smooth spherical particles, with noticeable roughness at their surface. The diameter of $\sim 250$ VLPs of each serotype shows a size distribution between 25 and $40 \mathrm{~nm}$, with DENV3 and DENV4 VLPs being slightly bigger ( 34$35 \mathrm{~nm}$ ) in size compared to DENV1 and DENV2 VLPs ( 29-30 nm).
DENV VLPs display similar epitopes than native virus To compare antibody epitopes displayed by DENV VLPs and infectious virions, we analyzed the binding of a large panel of well-characterized human and mouse derived mAbs (Table 1) to serially diluted VLPs and virions by capture ELISA. Cross-reactive mAbs 4G2 and 1 M7 were used to capture purified virus and VLPs. The tested mAbs vary from serotype specific (TS) or cross-reactive (CR) mAbs that bind epitopes of different complexities and the VLPs and purified fractions were derived from the same batch as used in the CBB, WB and TEM analysis. Figure 3 depicts binding to a virus/VLP concentration of $1.32 \mathrm{ng} / \mu \mathrm{l}$, which fell in the linear range of $\mathrm{mAb}$ binding, which was determined by serial dilutions (data not shown). Binding of the different mAbs to virus antigen can be qualitatively compared to the binding of the $\mathrm{mAbs}$ to purified VLPs. For DENV1, binding is observed for the DENV1 TS mAb 1F4 for both virus and VLP samples (Fig. 3a). With the exemption of C10, all CR mAbs such as $1 \mathrm{M} 7, \mathrm{EDE} 1$ (C8, C10), EDE2 (A11, B7), 1C19, 4G2 and 12C1.5 bind efficiently to DENV1 VLPs.

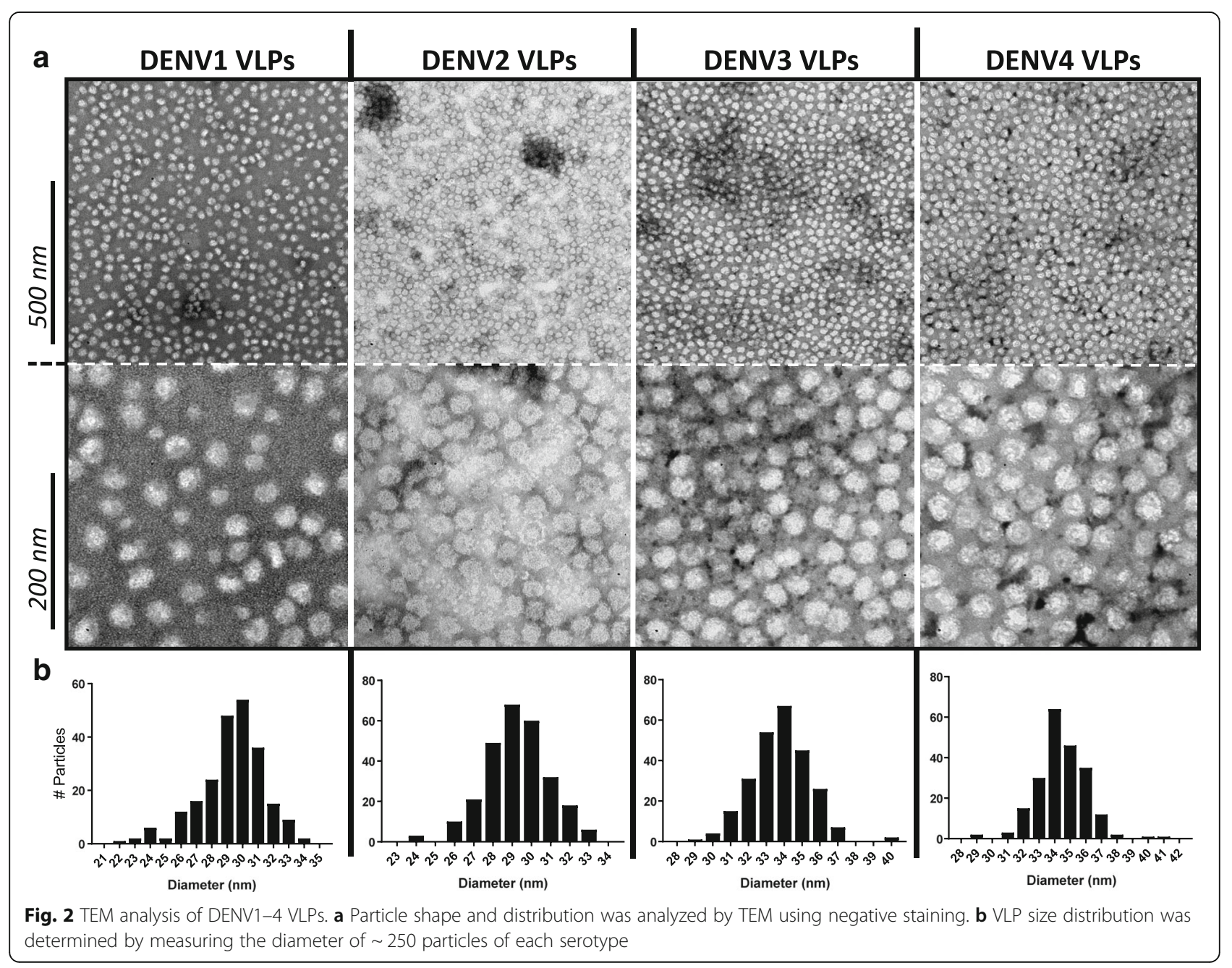




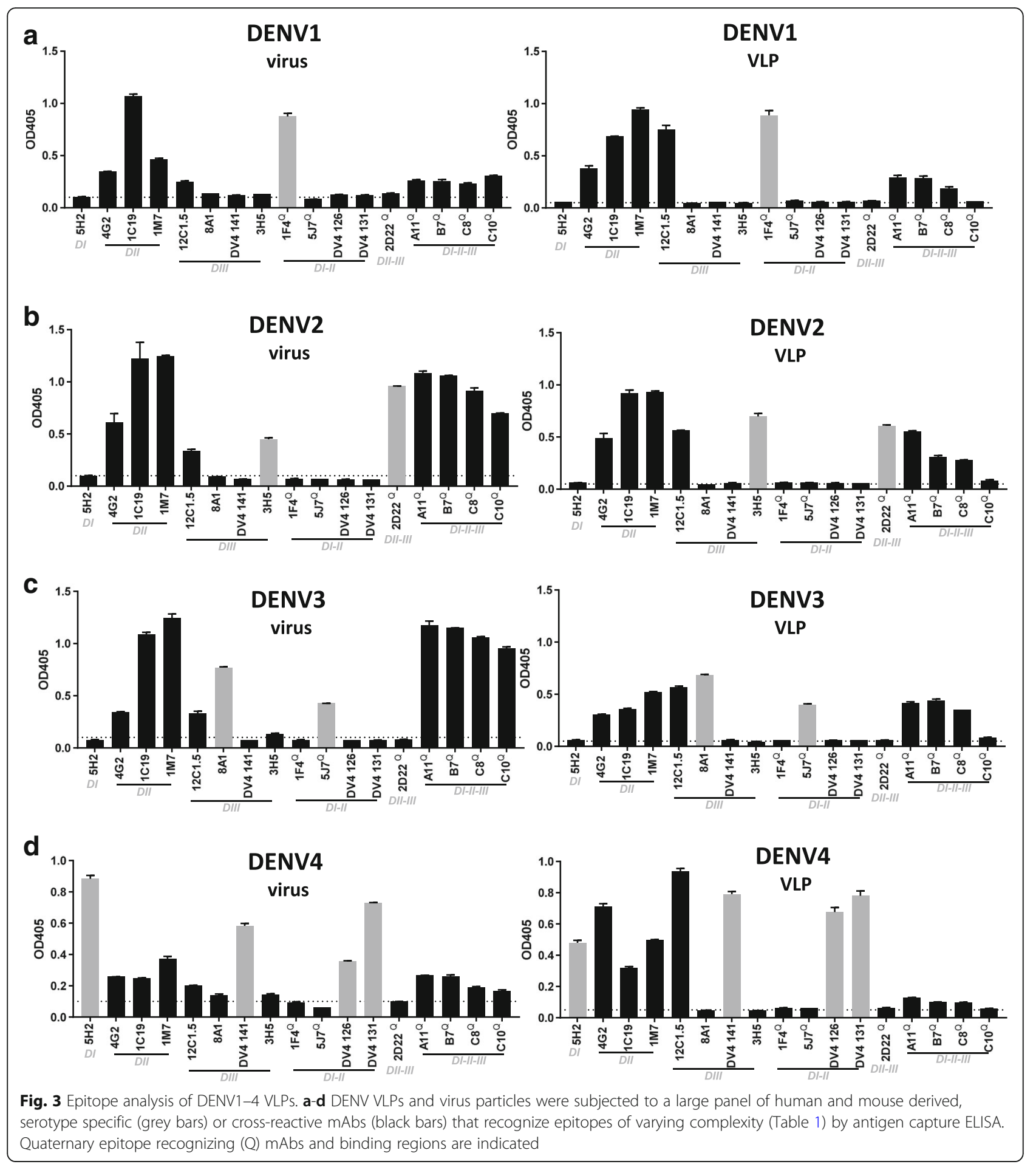

Similar serotype specificity was found for DENV2-4 VLPs. TS mAb 2D22 and 3H5 show specific binding to DENV2 VLPs (Fig. 3b), where binding is absent in the other serotypes. For DENV3, specific binding was observed by 5 J7 and 8A1 (Fig. 3c) and all CR mAbs bound both virus and VLPs. CR binding was observed to a lesser extent for DENV4 VLPs (Fig. 3d). Although the
TS mAbs 5H2, DV4 126, DV4 131 and DV4 141 bound DENV4 virus and VLPs accordingly, binding of e.g. EDE mAbs to DENV VLPs was marginal. Interestingly, only minor binding of C10 was observed to any of the VLPs.

Due to the experimental setup, binding signals of the same mAb to virus or VLP cannot be quantifiably compared. However, it is possible to get a relative insight 
into the differences in epitope exposure and abundance between virus and VLP. For this, we normalized the binding of each $\mathrm{mAb}$ to a well-characterized TS, quaternary epitope $\mathrm{mAb}$ of each of the 4 serotypes. By comparing the relative binding of each $\mathrm{mAb}$ between virus and VLP, one can demonstrate that certain epitopes are better represented on virus particles or VLPs. Future studies are needed for conclusive evidence, it does however give an indication on the relative epitope exposure.

Binding of each mAb was normalized to $1 F 4$ (DENV1) , 2D22 (DENV2), 5 J7 (DENV3) and 5H2 (DENV4) (Additional file 1). These are well characterized serotype specific mAbs that bind to quaternary epitopes. Normalized binding of each mAb to VLPs was subtracted from the normalized binding to purified virus, resulting in relative epitope binding (REB) (Fig. 4). Relative to 1F4 binding, $1 \mathrm{M} 7$ and 12C1.5 epitopes are better displayed on DENV1 VLPs than on DENV1 virus particles, whereas the $\mathrm{C} 10$ and $1 \mathrm{C} 19$ epitopes were better displayed on DENV1 virions than on VLPs (Fig. 4a). For DENV2, we observed enhanced binding of the EDE1 and EDE2 mAbs, relative to 2D22. Only $3 \mathrm{H} 5$ and $12 \mathrm{C} 1.5$ are significantly better recognized on DENV2 VLPs, compared to DENV2 virus (Fig. 4b). 12C1.5 binding was also found to be more proficient on DENV3 VLPs compared to virus particles. 1 M7, EDE $\mathrm{mAbs}$ and $1 \mathrm{C} 19$ binding was increased on DENV3 virus particles normalized to $5 \mathrm{J7}$ (Fig. 4c). Interestingly, many of the DV4 TS and CR mAbs such as 4G2 and 12C1.5 bind DENV4 VLPs better than virus particles, when normalized to $5 \mathrm{H} 2$.

\section{DENV infected patient sera is efficiently depleted by DENV VLPs}

To characterize infection or vaccine induced immune responses, it is essential to determine if DENV serotype specific or cross-reactive antibodies are responsible for the neutralizing activity in patient sera. These assays are traditionally performed by coating purified infectious virus particles to polystyrene beads, which are subsequently used to capture and deplete different antibody populations from serum samples. Using VLPs instead of infectious virus would offer many practical advantages in these serological assays. We depleted DENV patient convalescent sera (DT000) with DENV VLPs of each serotype individually. DT000 has been infected with multiple DENV serotypes $>20$ years ago and has been shown to efficiently neutralize all 4 serotypes [21]. DENV VLPs and purified virus were efficiently crosslinked to magnetic beads and used to deplete DT000 of all DENV specific antibodies. The ability of VLPs to deplete DENV sera was directly compared to that of virus particles (Fig. 5). VLPs of all DENV serotypes depleted DT000 sera equally well as virus particles (Fig. 5a). In accordance with depleted IgG levels, DT000 sera depleted with VLPs has completely lost its neutralizing activity (Fig. 5b).

\section{Discussion}

The immunogenic properties of DENV VLPs have been analyzed in animal models by several groups. However, little is known about E-protein organization on the surface of VLPs $[10,11]$. VLP epitope display has not yet been directly compared to that of virus particles and

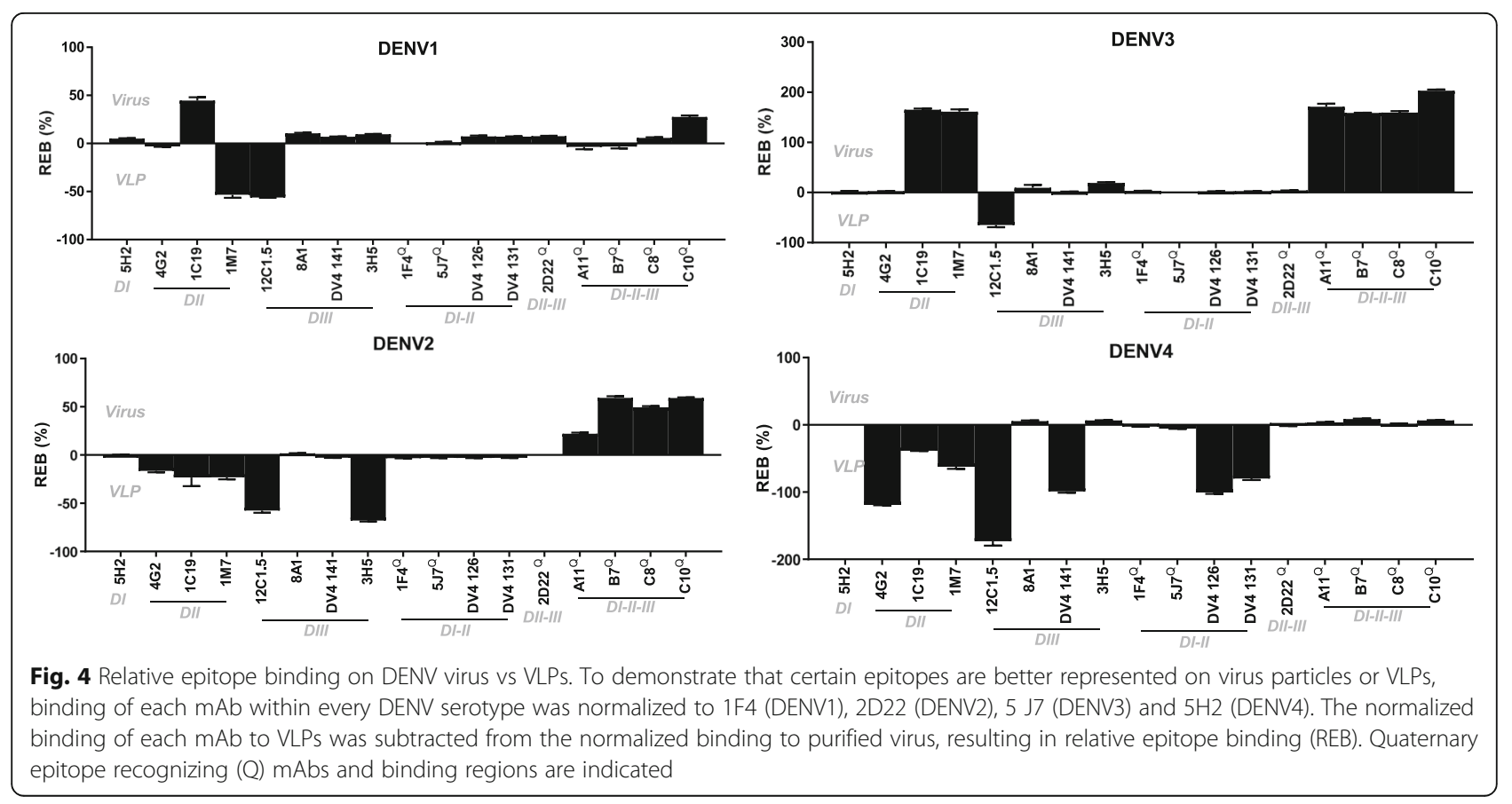




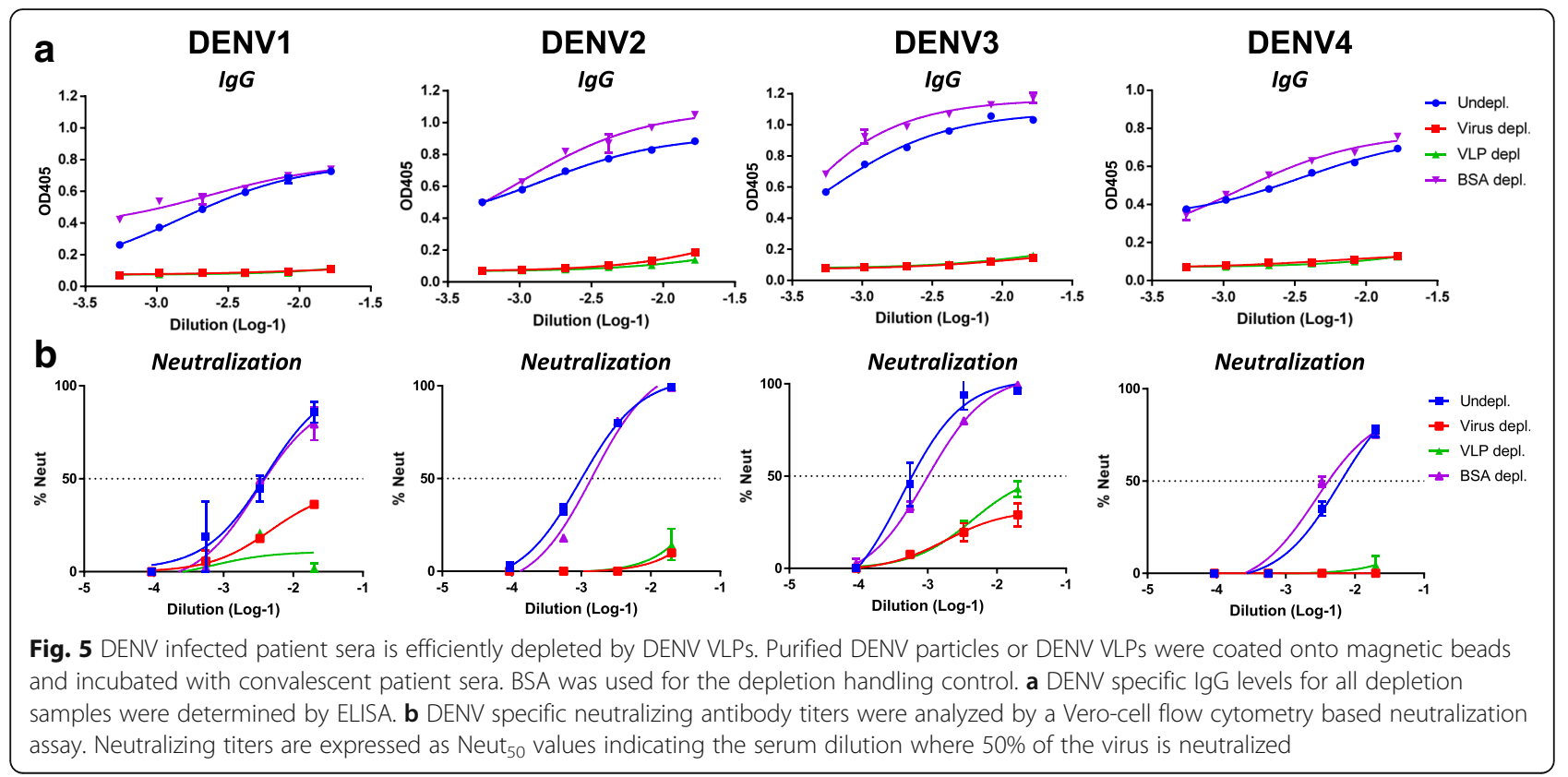

outside the use as vaccine antigens, VLP applicability as serological tools has been underappreciated. The terms subviral particle and VLP are often used to describe the same particle format, but can be considered different. In this study we refer to particles that do not contain a nucleocapsid and are produced after the expression of prM-E as VLPs. In our opinion, the term subviral particle is better used to describe the formation of smaller spherical particles obtained as a side product of wildtype infections.

DENV1-4 VLPs produced in mammalian cells efficiently display epitopes that have mapped on virus particles. TS and CR monoclonal antibodies isolated from different DENV patients with varying infection history bound to the VLPs indicating that native epitopes are present on the VLPs. In the low resolution cryo-EM structural data available on flavivirus virus-like particles or subviral particles, $30 \mathrm{E}$-dimers are assembled in a $T=$ 1 icosahedral lattice, different from the 90 E-dimers found on mature virus particles organized in a $T=3$ symmetry [12]. Our analysis here demonstrates that overall differences in arrangement of E-dimers on VLPs versus virions and the absence or presence of a nucleocapsid do not alter the display of most quaternary epitopes targeted by human antibodies.

The DENV VLPs were found to have a similar size distribution as the TBEV subviral particles. With particle diameters of $\sim 29-34 \mathrm{~nm}$, the VLPs are considerably smaller in size than natural virus particles $(\sim 50 \mathrm{~nm})[4,12,22]$. The minor VLP size differences between serotypes could be attributed to maturation dissimilarities, however, as the highly concentrated VLPs are not perfect spheres and have structural irregularities, the measurements of diameters might be error prone. Future structural studies are needed to confirm the observed differences in DENV VLP diameter.

Human mAb 1F4 is DENV1 specific and although it only binds the virus and not the E-monomer, its footprint has been mapped within one E-monomer and not across neighboring E-proteins within the homodimer [7]. Despite differences in size and prM content, 1F4 bound equally well to DENV1 VLPs and purified virus. Similar results were found for 2D22 (DENV2), 5 J7 (DENV3) and 5H2 (DENV4). 2D22 is a potent neutralizing antibody and binds epitopes that span across the Eprotein dimer, blocking envelope reorganization necessary for viral fusion [5]. DENV3 specific mAb $5 \mathrm{J7}$ has a footprint that spans across neighboring E-dimers including residues at the EDI/EDII hinge region [23]. Binding of $5 \mathrm{~J} 7$ to DENV3 VLPs strongly indicates that E-dimers interact and form poly-dimer structures similar to the rafts found on virion surfaces. For long, $5 \mathrm{H} 2$ was the only DENV4 specific highly neutralizing $\mathrm{mAb}$ of which the binding footprint has been mapped. This chimpanzee derived $\mathrm{mAb}$ docks within EDI of E [24]. It does not bind monomeric E-proteins, but efficiently binds both DENV4 virus and VLPs. Recent studies have identified new DENV4 TS mAbs that bind E-protein in ranging complexity [8]. DV4 126 and DV4 131 are highly neutralizing and their quaternary footprint was mapped to the EDI/EDII hinge region. Just like $5 \mathrm{~J} 7$, these mAbs do not bind monomeric E-proteins, but recognize virus and VLPs.

We used 1F4, 2D22, $5 \mathrm{~J} 7$ and $5 \mathrm{H} 2$ to normalize the binding of all the other mAbs to both virus and VLP, allowing for a relative comparison between epitope 
availability on virus vs VLPs. Relative to these mAbs we see that the EDIII binding mAbs $12 \mathrm{C} 1.5$ and $3 \mathrm{H} 5$ bind better to VLPs, indicating that the EDIII might be more exposed on VLPs. The quaternary CR EDE epitopes are relatively better presented on DENV2-3 virus particles. In particular EDE1-C10 binding has a strong preference for virus particles, due to the absence of binding to VLPs of all serotypes. It remains unclear why $\mathrm{C} 10$ does not bind VLPs, while the other EDE mAbs, that share a very similar footprint, bind efficiently.

The maturity of virus particles and VLPs affects epitope display as exemplified by the fusion loop binding CR mAb 4G2. During virus replication, the pr peptide associates with the fusion loop in $\mathrm{E}$, shielding it from premature low-pH induced fusion with host cell membranes [25]. Our analysis indicates that the fusion loop is efficiently exposed on DENV4 VLPs, which is in accordance to the undetectable prM levels in DENV4 VLPs. Differences in prM levels between DENV2-3 VLPs and virus might have similar steric hindrance effects on the EDE mAbs. However, this requires further structural analysis. In general, epitopes present on the fusion loop domain, EDIII and DI/DII/DIII spanning regions are all represented on DENV VLP surfaces.

The footprints of many mAbs have been mapped on dimers generated from soluble monomeric $\mathrm{E}$ proteins. Soluble E monomers crystallize into dimers and do not contain prM. Even though it is assumed that the crystallized dimers are structurally similar to E-dimers found on virus particles, they might differ when part of complex multiprotein complexes on VLP envelopes. Future studies should focus on DENV VLP protein structures to answer these questions.

The VLPs and virus particles were captured by mAbs 4G2 and 1 M7, suggesting a bias for fusion loop exposed particles. However, using other capturing mAbs, the bias would be skewed towards particles displaying that specific epitope. Using other wellcharacterized mAbs, we have shown that DENV VLPs display an epitope landscape very similar to that found on virus particles. Depletion studies using VLPs as a depletion antigen translate this finding to polyclonal sera of DENV infected patients. Secondary infected serum was efficiently depleted from all TS and CR (non)-neutralizing antibodies. Serum depletions are usually performed using infectious purified virus antigen conjugated to microbeads. However the use of VLPs has practical benefits over the use of purified antigen. Issues of infectious virus production and purification and virus leaching into the serum during handling are not present when using VLPs. Additionally, VLPs are more easily genetically adapted and are therefore valuable tools in flavivirus $\mathrm{pAb}$ and $\mathrm{mAb}$ mapping and serology.

\section{Conclusions}

Flavivirus VLP based vaccines are amongst the leading candidates in ongoing vaccine studies. Understanding the structure of VLPs is essential for interpreting the antibody response in vaccinees. VLPs also have potential value as diagnostic reagents. Besides, VLPs can be produced as a byproduct of natural infection. Therefore, the structure of VLPs also becomes important from the standpoint of virus assembly. By exploiting antibodies and insights high resolution structure of dengue virions, this study aids in further understanding the antigenic landscape of DENV VLPs and presents a comparative antigenic surface view of VLPs in respect to virus particles.

\section{Additional file}

Additional file 1: Normalized antibody binding to DENV virus particles and VLPs. The binding of each mAb to virus (black bars) or VLPs (grey bars) within every DENV serotype was normalized to 1F4 (DENV1), 2 D22 (DENV2), $5 \mathrm{~J} 7$ (DENV3) and 5H2 (DENV4). (PDF $220 \mathrm{~kb}$ )

\section{Acknowledgements}

Not applicable.

\section{Funding}

These studies were supported by NIAID grant 1-R01-Al107731-01 (PI A. de Silva, UNC), the European Union Zika Plan Research Consortium and the CDC grant 200-2017-93142 (PI A. de Silva, UNC).

\section{Availability of data and materials}

All data generated or analyzed during this study are included in this published article and its supplementary information files.

Authors' contributions

SWM designed the study, has conducted the majority of experiments and wrote the manuscript. AT, LW and MS have assisted in experiments and optimized protocols. HH kindly supplied the VLPs and reviewed the manuscript. ASdS has critically reviewed the manuscript and helped design the study. All authors read and approved the final manuscript.

Ethics approval and consent to participate

Not applicable.

Consent for publication

Not applicable.

Competing interests

$\mathrm{HH}$ is the director of research for The Native Antigen Company that has supplied the VLPS.

\section{Publisher's Note}

Springer Nature remains neutral with regard to jurisdictional claims in published maps and institutional affiliations.

\section{Author details}

${ }^{1}$ Department of Microbiology and Immunology, University of North Carolina, Chapel Hill, USA. ${ }^{2}$ The Native Antigen Company, Kidlington, Oxford, UK. 
Received: 25 January 2018 Accepted: 20 March 2018

\section{Published online: 02 April 2018}

\section{References}

1. Bhatt S, Gething PW, Brady OJ, Messina JP, Farlow AW, Moyes CL, Drake JM, Brownstein JS, Hoen AG, Sankoh O, et al. The global distribution and burden of dengue. Nature. 2013;496:504-7.

2. Thomas SJ, Endy TP. Critical issues in dengue vaccine development. Curr Opin Infect Dis. 2011;24:442-50

3. Wilder-Smith A, Ooi EE, Vasudevan SG, Gubler DJ. Update on dengue: epidemiology, virus evolution, antiviral drugs, and vaccine development. Curr Infect Dis Rep. 2010;12:157-64.

4. Lindenbach B, Rice C. Flaviviridae: the viruses and their replication. Fields Virology. 2001;1:991-1041.

5. Fibriansah G, Ibarra KD, Ng TS, Smith SA, Tan JL, Lim XN, Ooi JS, Kostyuchenko VA, Wang J, de Silva AM, et al. DENGUE VIRUS. Cryo-EM structure of an antibody that neutralizes dengue virus type 2 by locking $E$ protein dimers. Science. 2015;349:88-91.

6. Dejnirattisai W, Wongwiwat W, Supasa S, Zhang X, Dai X, Rouvinski A, Jumnainsong A, Edwards C, Quyen NT, Duangchinda T, et al. A new class of highly potent, broadly neutralizing antibodies isolated from viremic patients infected with dengue virus. Nat Immunol. 2015;16:170-7.

7. Fibriansah G, Tan JL, Smith SA, de Alwis AR, Ng TS, Kostyuchenko VA, Ibarra KD, Wang J, Harris E, de Silva A, et al. A potent anti-dengue human antibody preferentially recognizes the conformation of $E$ protein monomers assembled on the virus surface. EMBO Mol Med. 2014;6:358-71.

8. Nivarthi UK, Kose N, Sapparapu G, Widman D, Gallichotte E, Pfaff JM, Doranz BJ, Weiskopf D, Sette A, Durbin AP: Mapping the Human Memory B Cell and Serum Neutralizing Antibody Responses to DENV4 Infection and Vaccination. J Virol.2016:JVI. 02041-02016.

9. Liu Y, Si B, Hu Y, Zhang Y, Yang Y, Zhu Q. Expression of tick-borne encephalitis virus prM-E protein in insect cells and studies on its antigenicity. Zhonghua shi yan he lin chuang bing du xue za zhi= Zhonghua shiyan he linchuang bingduxue zazhi= Chin J Exp Clin Virol. 2005;19:335.

10. Liu Y, Zhou J, Yu Z, Fang D, Fu C, Zhu X, He Z, Yan H, Jiang L. Tetravalent recombinant dengue virus-like particles as potential vaccine candidates: immunological properties. BMC Microbiol. 2014;14:233.

11. Urakami A, Ngwe Tun MM, Moi ML, Sakurai A, Ishikawa M, Kuno S, Ueno R, Morita K, Akahata W. Envelope-modified tetravalent dengue virus-like particle vaccine: implication for flavivirus vaccine design. J Virol. 2017;

12. Ferlenghi I, Clarke M, Ruttan T, Allison SL, Schalich J, Heinz FX, Harrison SC, Rey FA, Fuller SD. Molecular organization of a recombinant subviral particle from tick-borne encephalitis virus. Mol Cell. 2001;7:593-602.

13. Pijlman GP. Enveloped virus-like particles as vaccines against pathogenic arboviruses. Biotechnol J. 2015;10:659-70.

14. Metz S, Gardner IA, Geertsema C, Thuy L, Goh L, Suhrbier A, Vlak J, Pijlman G. Effective chikungunya virus-like particle vaccine produced in insect cells. PLoS Negl Trop Dis. 2013; In press

15. Akahata W, Yang ZY, Andersen H, Sun S, Holdaway HA, Kong WP, Lewis MG, Higgs S, Rossmann MG, Rao S, Nabel GJ. A virus-like particle vaccine for epidemic chikungunya virus protects nonhuman primates against infection. Nat Med. 2010;16:334-8

16. Boigard H, Alimova A, Martin GR, Katz A, Gottlieb P, Galarza JM. Zika viruslike particle (VLP) based vaccine. PLoS Negl Trop Dis. 2017;11:e0005608.

17. Yamaji H, Konishi E. Production of Japanese encephalitis virus-like particles using insect cell expression systems. Methods Mol Biol. 2016;1404:365-75.

18. Putnak R, Barvir DA, Burrous JM, Dubois DR, D'Andrea VM, Hoke CH, Sadoff JC, Eckels KH. Development of a purified, inactivated, dengue-2 virus vaccine prototype in Vero cells: immunogenicity and protection in mice and rhesus monkeys. J Infect Dis. 1996;174:1176-84.

19. Metz SW, Tian S, Hoekstra G, Yi X, Stone M, Horvath K, Miley MJ, DeSimone J, Luft CJ, de Silva AM. Precisely molded nanoparticle displaying DENV-E proteins induces robust serotype-specific neutralizing antibody responses. PLoS Negl Trop Dis. 2016;10:5071-88.

20. Kraus AA, Messer W, Haymore LB, de Silva AM. Comparison of plaque- and flow cytometry-based methods for measuring dengue virus neutralization. J Clin Microbiol. 2007:45:3777-80

21. Patel B, Longo P, Miley MJ, Montoya M, Harris E, de Silva AM. Dissecting the human serum antibody response to secondary dengue virus infections. PLoS Negl Trop Dis. 2017;11:e0005554.
22. Kuhn RJ, Zhang W, Rossmann MG, Pletnev SV, Corver J, Lenches E, Jones CT, Mukhopadhyay S, Chipman PR, Strauss EG, et al. Structure of dengue virus: implications for flavivirus organization, maturation, and fusion. Cell. 2002; 108:717-25.

23. de Alwis R, Smith SA, Olivarez NP, Messer WB, Huynh JP, Wahala WM, White L, Diamond MS, Baric RS, Crowe JE Jr, de Silva AM. Identification of human neutralizing antibodies that bind to complex epitopes on dengue virions. Proc Natl Acad Sci U S A. 2012;109:7439-44.

24. Cockburn JJ, Navarro Sanchez ME, Goncalvez AP, Zaitseva E, Stura EA, Kikuti CM, Duquerroy S, Dussart P, Chernomordik LV, Lai CJ, Rey FA. Structural insights into the neutralization mechanism of a higher primate antibody against dengue virus. EMBO J. 2012;31:767-79.

25. Li L, Lok SM, Yu IM, Zhang Y, Kuhn RJ, Chen J, Rossmann MG. The flavivirus precursor membrane-envelope protein complex: structure and maturation. Science. 2008;319:1830-4.

26. Henchal EA, McCown JM, Burke DS, Seguin MC, Brandt WE. Epitopic analysis of antigenic determinants on the surface of dengue-2 virions using monoclonal antibodies. Am J Trop Med Hyg. 1985;34:162-9.

27. Wahala WM, Donaldson EF, de Alwis R, Accavitti-Loper MA, Baric RS, de Silva AM. Natural strain variation and antibody neutralization of dengue serotype 3 viruses. PLoS Pathog. 2010;6:e1000821.

28. Smith SA, de Alwis AR, Kose N, Harris E, Ibarra KD, Kahle KM, Pfaff JM, Xiang $X$, Doranz BJ, de Silva AM, et al. The potent and broadly neutralizing human dengue virus-specific monoclonal antibody 1C19 reveals a unique crossreactive epitope on the bc loop of domain II of the envelope protein. MBio. 2013;4:e00873-00813.

29. Swanstrom JA, Plante JA, Plante KS, Young EF, McGowan E, Gallichotte EN, Widman DG, Heise MT, de Silva AM, Baric RS. Dengue virus envelope dimer epitope monoclonal antibodies isolated from dengue patients are protective against Zika virus. MBio. 2016;7:1123-31.

30. Smith SA, de Alwis AR, Kose N, Jadi RS, de Silva AM, Crowe JE Jr. Isolation of dengue virus-specific memory $B$ cells with live virus antigen from human subjects following natural infection reveals the presence of diverse novel functional groups of antibody clones. J Virol. 2014;88:12233-41.

31. Rouvinski A, Guardado-Calvo P, Barba-Spaeth G, Duquerroy S, Vaney MC, Kikuti CM, Navarro Sanchez ME, Dejnirattisai W, Wongwiwat W, Haouz A, et al. Recognition determinants of broadly neutralizing human antibodies against dengue viruses. Nature. 2015;520:109-13.

32. Pitcher TJ, Sarathy W, Matsui K, Gromowski GD, Huang CY, Barrett AD. Functional analysis of dengue virus (DENV) type 2 envelope protein domain 3 type-specific and DENV complex-reactive critical epitope residues. J Gen Virol. 2015:96:288-93.

33. Zhou Y, Austin SK, Fremont DH, Yount BL, Huynh JP, de Silva AM, Baric RS, Messer WB. The mechanism of differential neutralization of dengue serotype 3 strains by monoclonal antibody 8A1. Virology. 2013;439:57-64.

\section{Submit your next manuscript to BioMed Central and we will help you at every step:}

- We accept pre-submission inquiries

- Our selector tool helps you to find the most relevant journal

- We provide round the clock customer support

- Convenient online submission

- Thorough peer review

- Inclusion in PubMed and all major indexing services

- Maximum visibility for your research

Submit your manuscript at www.biomedcentral.com/submit
Biomed Central 